\title{
Grief in critical care nurses after pediatric suffering and death
}

\author{
Kelley A. Groves ${ }^{1 \wedge}$, Aminat Adewumi ${ }^{2}$, Cynthia A. Gerhardt ${ }^{2}$, Micah A. Skeens ${ }^{2}$, Markita L. Suttle $^{1}$ \\ ${ }^{1}$ Division of Pediatric Critical Care Medicine, Nationwide Children's Hospital, Columbus, OH, USA; ${ }^{2}$ Center for Biobehavioral Health, Nationwide \\ Children's Hospital, Columbus, OH, USA \\ Contributions: (I) Conception and design: KA Groves, CA Gerhardt, ML Suttle; (II) Administrative support: A Adewumi; (III) Provision of study \\ materials or patients: KA Groves, CA Gerhardt, ML Suttle; (IV) Collection and assembly of data: KA Groves, CA Gerhardt, ML Suttle; (V) \\ Data analysis and interpretation: KA Groves, A Adewumi, CA Gerhardt, ML Suttle; (VI) Manuscript writing: All authors; (VII) Final approval of \\ manuscript: All authors. \\ Correspondence to: Kelley A. Groves, MD. Hassenfeld Children's Hospital at NYU Langone, 430 E $34^{\text {th }}$ St, New York, NY 10016 , USA. \\ Email: Kelley.Groves@nyulangone.org.
}

Background: Working in the pediatric intensive care unit (PICU) exposes nurses to intense and recurrent experiences with loss. Such experiences may result in unresolved grief or despair among these providers. Although previous studies have explored grief within the nursing profession, few have focused on grief following the death of children in the PICU, where sudden or traumatic deaths are more frequent. The aim of this study was to characterize the degree to which pediatric critical care (PCC) nurses experience symptoms of grief or distress following the suffering and/or death of a patient in the PICU.

Methods: An email invited PICU nurses at a large free standing children's hospital to complete an online survey with demographic questions and an open-ended, qualitative question about grief experiences. Research team members coded open-ended responses, using thematic content analysis. Final themes were further validated via member checking.

Results: Of the 104 participants, most were Caucasian (96.3\%), female (97\%), bedside (83.5\%) nurses with a bachelor's degree (85.4\%). Participants had variable years of experience and included both day (59.6\%) and night (40.4\%) shift nurses. After detailed analysis, the research team identified four major themes among pediatric critical care (PCC) nurses when asked about grief symptoms and distress following the suffering or death of a patient in the PICU: (I) continuum of emotional responses; (II) emotional prompts; (III) coping, and (IV) resilience.

Conclusions: Many PICU nurses were profoundly affected by the death of their patients, while others offered strategies that fostered resilience. Understanding the impact of repeated loss on these specialized nurses may inform the development of more effective grief and bereavement support programs for healthcare providers.

Keywords: Critical care; death; grief; pediatric; suffering

Submitted Nov 03, 2021. Accepted for publication Jan 14, 2022.

doi: 10.21037/apm-21-3225

View this article at: https://dx.doi.org/10.21037/apm-21-3225

\section{Introduction}

The fundamental goal of critical care is to save lives, but despite this, critical care nurses encounter death on a regular basis. Although the healthcare team strives to preserve life; naturally, a critically ill child requiring intensive supportive care may not survive. Repeated exposure to patient death and suffering provokes a spectrum of intense physical and emotional responses (1-5).

\footnotetext{
$\wedge$ ORCID: 0000-0002-1189-7314.
} 
These responses may be amplified in pediatrics, where nurses not only care for the most vulnerable patients, but their families as well.

Frequent patient deaths expose nurses to intense and recurrent experiences with loss, which may result in unresolved grief or despair (6-8). Nurses may experience feelings of personal loss at the time of a patient death $(6,8)$, but not feel as if they have a socially recognized right, role, or the capacity to grieve over their patients $(9,10)$. Nurses often ignore feelings of grief leading to unrecognized and unaddressed grief that may become chronic and cumulative (11). Physical symptoms of cumulative grief may develop and include; physical illness, substance abuse, suicidal thoughts, apathy, poor self-esteem, depression, and anxiety $(12,13)$. Cumulative grief may cause nurses to emotionally detach or overinvest in patients' lives (14). Grief in nursing is associated with burnout, decreased job satisfaction, increased staff turnover, interpersonal conflict and compassion fatigue (15-17).

Specific to pediatrics, the way nurses respond to grief is associated with extraneous factors (18). Factors contributing to the grief response can include, previous death experiences, personal grief, professional nursing attitudes and workplace environment (19).

Although, previous studies have explored grief within the nursing profession (3,4,20-23), few have focused on grief following the death and/or suffering of a child in the pediatric intensive care unit (PICU). Witnessing the suffering of a child can negatively affect healthcare professionals and is a significant contributor to moral distress $(24,25)$. Understanding the nature of grief within this group of specialized nurses may provide organizations with tools for building more impactful grief and bereavement support programs for healthcare providers. The aim of this study was to characterize the degree to which pediatric critical care (PCC) nurses experience symptoms of grief or distress following the suffering and/or death of a patient in the PICU. We present the following article in accordance with the SRQR reporting checklist (available at https://apm.amegroups.com/article/ view/10.21037/apm-21-3225/rc).

\section{Methods}

Data for this paper was part of a larger study examining the well-being of nurses in the PICU. All pediatric critical care nurses working in the PICU at a large, pediatric institution in the Midwest region of the United States of America, were eligible for participation in this cross-sectional study. The PICU is a 54-bed multidisciplinary unit with over 3,000 admissions per year. The institution is designated as a Level 1 trauma center, certified pediatric burn center, and provides care to a diverse patient population, including recipients of solid organ and bone marrow transplant, as well as patients requiring advanced organ support such as extracorporeal membrane oxygenation (ECMO) and continuous renal replacement therapy (CRRT). To provide additional description of the study setting in comparison to other institutions, we referenced the Virtual Pediatric Systems (VPS) database; a database with information on over 1 million PICU admissions, from over 130 hospitals addressing all aspects of PCC medicine (26). According to VPS for the year of the survey [2019], unadjusted mortality (number of deaths divided by the population at risk) in the PICU was $1.63 \%$ (52/3,192 admissions), compared to $2.06 \%$ (2,713/131,650 admissions) for PICU admissions across all institutions included in the national VPS database. Regarding institutional nursing support, there is a wellestablished second victim program embedded within the institution, and all employees have access to a finite number of free professional counseling sessions per year. The PICU has occasional, inconsistent debriefings but no formalized process for this after a patient death.

\section{Data collection}

Following approval from the Institutional Review Board, which included ethical approval, a purposive sample, which included all PICU nurses at a single institution were invited to participate in the study. PICU nurses received an email with an information sheet explaining the study purpose, procedures, risks, benefits, and their rights as a research volunteer. Participants opted in by clicking on the link to the online survey and had 6-week to complete it. The study was conducted in accordance with the Declaration of Helsinki (as revised in 2013). The study was approved by the Institutional Review Board of Nationwide Children's Hospital (\#00000193) and informed consent was obtained by participant decision to complete the electronic survey embedded within the participant information sheet.

Upon completion of the survey participants received a gift card for the hospital coffee shop. The ten-minute online survey included a series of demographic questions, and a qualitative question with free text responses about their grief experiences as a PICU nurse. The qualitative question was developed after several discussions with 
Table 1 Participant demographics

\begin{tabular}{|c|c|}
\hline Demographics & n (\%) \\
\hline \multicolumn{2}{|l|}{ Gender } \\
\hline Female & $97(94.2)$ \\
\hline Male & $6(5.83)$ \\
\hline Age, median [IQR] & $29.0[25.0,35.2]$ \\
\hline \multicolumn{2}{|l|}{ Race } \\
\hline African-American & $2(1.92)$ \\
\hline Asian & $1(0.96)$ \\
\hline Caucasian & $100(96.2)$ \\
\hline Other non-Caucasian & $1(0.96)$ \\
\hline \multicolumn{2}{|l|}{ Ethnicity } \\
\hline Hispanic & $3(2.91)$ \\
\hline Non-Hispanic & $100(97.1)$ \\
\hline \multicolumn{2}{|l|}{ Household income } \\
\hline$\$ 26,000-50,000$ & $9(8.74)$ \\
\hline$\$ 51,000-75,000$ & $38(36.9)$ \\
\hline$\$ 76,000-100,000$ & $17(16.5)$ \\
\hline$\$ 101,000-150,000$ & $20(19.4)$ \\
\hline$\$ 150,000+$ & $19(18.4)$ \\
\hline \multicolumn{2}{|l|}{ Partner } \\
\hline No partner & $27(26.0)$ \\
\hline Partner & $77(74.0)$ \\
\hline \multicolumn{2}{|l|}{ Children } \\
\hline No & $57(55.9)$ \\
\hline Yes & $45(44.1)$ \\
\hline
\end{tabular}

bedside nurses and nursing managers regarding the emotional impact on healthcare workers after adverse patient events in the PICU. The question for our qualitative analysis was, "Some nurses who witness the suffering or death of patients in the PICU may experience grief symptoms or distress, while others may experience few if any symptoms. Please describe the degree to which you experience grief symptoms or distress following the suffering or death of a patient in the PICU". The study was done via electronic survey due to PCC nurses indicating a higher level of participation if the study was done electronically, as well as the importance of participant anonymity with a primarily PCC research team.

\section{Statistical analysis}

Thematic content analysis was conducted by a PCC attending level physician (MS), PCC senior fellow physician (KG), and a bachelor's level research assistant (AA). Transcripts of open-ended responses were coded, using a constant comparative method in batches of 25 responses, over several different in-person meetings. In these meetings, the research team would discuss, refine, and synthesize codes and themes until saturation was achieved. Discrepancies between team members were resolved by re-reading individual responses together and reaching consensus through discussion. Final themes and supporting responses were reviewed by a pediatric psychologist (CG), with expertise in the use of qualitative methods in behavioral research. Final themes were further validated via member checking. Member checking consisted of brief, inperson interviews with participants who were purposively chosen by the research team to ensure diversity within the group. Detailed notes were transcribed and reviewed by all research team members. No adjustments were required after completion of member checking process.

\section{Results}

A total of 104 of 210 (49.5\%) nurses completed the survey. Most were Caucasian ( $\mathrm{n}=97,96.3 \%)$, female $(\mathrm{n}=100,97 \%)$, bedside $(\mathrm{n}=86,83.5 \%)$ nurses with a bachelor's degree $(\mathrm{n}=88$, $85.4 \%$ ). The Caucasian, female prevalence was expected, as this is representative of PCC nurse workforce at the institution. Participants included both day $(\mathrm{n}=62,59.6 \%)$ and night ( $\mathrm{n}=42,40.4 \%)$ shift nurses (Tables 1,2).

Thematic content analysis revealed the emergence of four primary themes in response to the question about grief symptoms and distress following the suffering or death of a patient in the PICU. Themes related to the experience included: (I) continuum of emotional responses, (II) emotional prompts, (III) coping strategies, and (IV) resilience (Table 3).

\section{Continuum of emotional responses}

A prevailing theme identified by nurses was the experience of a continuum of emotional responses, which were further delineated on a spectrum of impact and described as minimal, transient, or persistent/intrusive (i.e., specific, repetitive thoughts related to trauma) emotional responses. Some nurses experienced an emotional response with 
Table 2 Participant education and experience level summarized.

\begin{tabular}{|c|c|}
\hline Education/experience level & n (\%) \\
\hline \multicolumn{2}{|l|}{ Education } \\
\hline Associates & $5(4.85)$ \\
\hline Bachelors & $88(85.4)$ \\
\hline Masters & $10(9.71)$ \\
\hline \multicolumn{2}{|l|}{ Years nursing } \\
\hline$\leq 3$ years & $35(34.0)$ \\
\hline$>3-5$ years & $16(15.5)$ \\
\hline $6-10$ years & $20(19.4)$ \\
\hline$>10$ years & $32(31.1)$ \\
\hline \multicolumn{2}{|l|}{ Years PICU* } \\
\hline$\leq 3$ years & 38 (37.3) \\
\hline$>3-5$ years & $19(18.6)$ \\
\hline $6-10$ years & $20(19.6)$ \\
\hline$>10$ years & $25(24.5)$ \\
\hline \multicolumn{2}{|l|}{ Role } \\
\hline Administrative & $1(0.97)$ \\
\hline Bedside & $86(83.5)$ \\
\hline Charge nurse & $11(10.7)$ \\
\hline Research & $2(1.94)$ \\
\hline Resource nurse & $3(2.91)$ \\
\hline \multicolumn{2}{|l|}{ Location } \\
\hline Both $\mathrm{H} 2 \mathrm{~B}$ and $\mathrm{H} 8 \mathrm{~B}$ & $1(0.96)$ \\
\hline $\mathrm{H} 2 \mathrm{~B}$ & $66(63.5)$ \\
\hline H8B & $37(35.6)$ \\
\hline \multicolumn{2}{|l|}{ Shift } \\
\hline Day & $62(59.6)$ \\
\hline Night & $42(40.4)$ \\
\hline \multicolumn{2}{|l|}{ Formal EOL ${ }^{* *}$ training } \\
\hline No & $53(51.5)$ \\
\hline Yes & $50(48.5)$ \\
\hline \multicolumn{2}{|l|}{ Debriefing session } \\
\hline No & $84(83.2)$ \\
\hline Yes & $17(16.8)$ \\
\hline
\end{tabular}

${ }^{*}$, pediatric intensive care unit; ${ }^{* *}$, end of life. minimal impact and shared statements like, "I do not feel many symptoms", or "I have dealt with these experiences in a healthy manner and not suffered from grief or distress". Others reported a transient response which subsided with time, such as "I like to let myself think of the patient and family for a little while to cope with their death, but I do try to detach myself from thinking about it for too long”, and, "There's always grief. Many times, it's crying and accepting that this happened before moving on". Some expressed persistent/intrusive emotional responses highlighted by statements like, "After witnessing suffering, I often feel emotionally drained for sometimes days after the event. I also often think about the event for days to weeks after" or "I do think about the kids that I have taken care of or been there when they have passed. I can think about someone who died years ago randomly. They don't fully leave my mind". Some experience persistent daily grief, "It is rare for me to have a night where I do not have some sort of dream about work, almost always distressing". Additional participant quotes related to this theme can be found in Table 3.

\section{Emotional prompts}

Another theme expressed by nursing staff was experiencing emotional prompts, dichotomized by those which compound (increase) versus alleviate (decrease) emotional responses. Certain quotes will be highlighted here, however additional quotes can be found in Table 3. Compounding prompts may be identified as mirrored experiences, "The symptoms for me are the worst when I can imagine myself and kids in that situation" and "Now, after having my own children, I find distress is so much quicker to surface, and the distress and grief are so much more powerful. It's so easy to place myself in the shoes of the patient's parents and think 'what if', and it is terrifying on a whole new level". Personal relationships with the patient and family also magnified emotional responses, as evidenced by comments like, "The level of grief and distress I feel following a patient death mainly depends on the relationship I have with the patient and/or their family. It's all about connection for me" and "I have always experienced distress with suffering and grieved over patients' deaths-especially patients I have cared for long-term whom I've grown close to, or when I've formed special relationships with their families". Lastly, perceived 


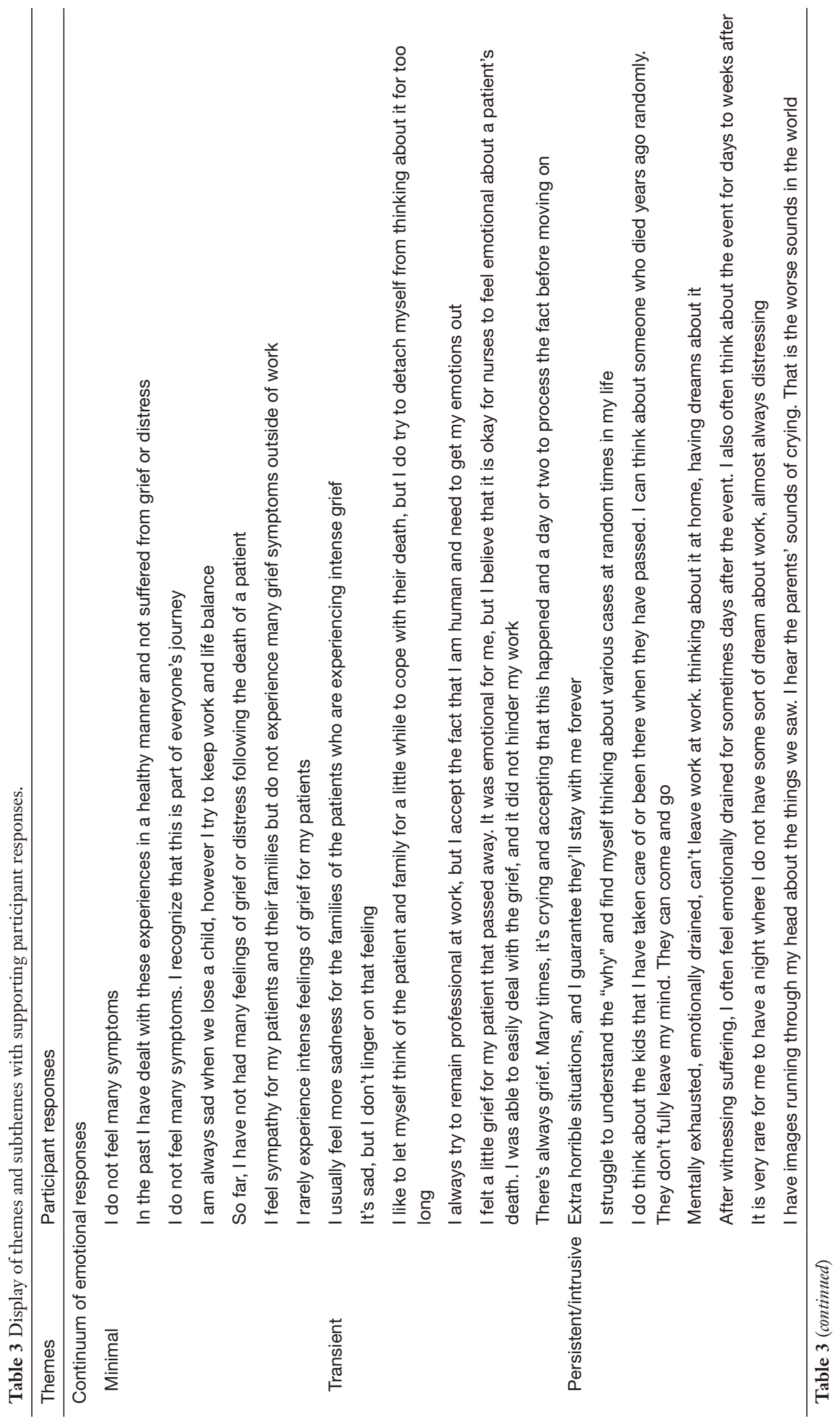




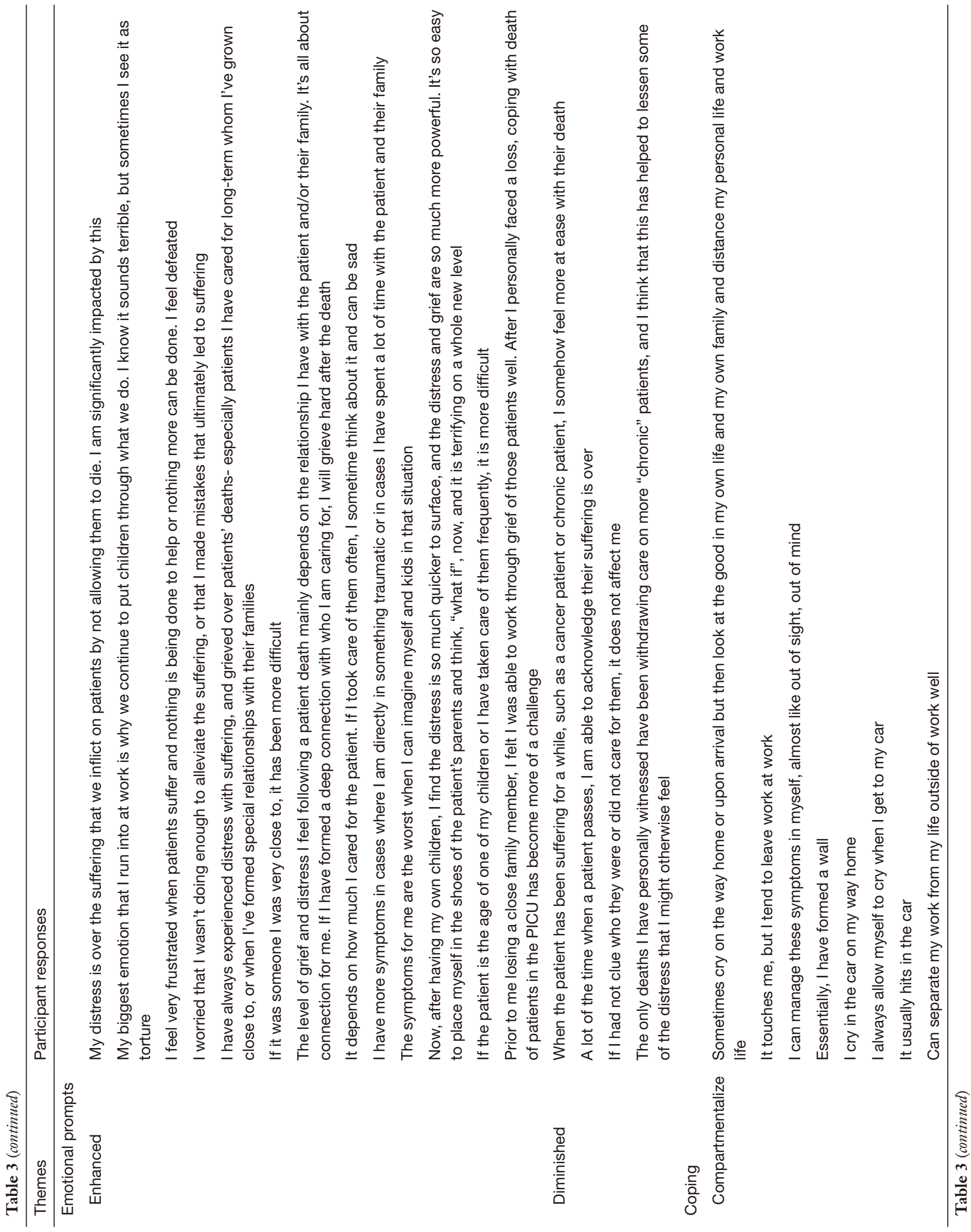




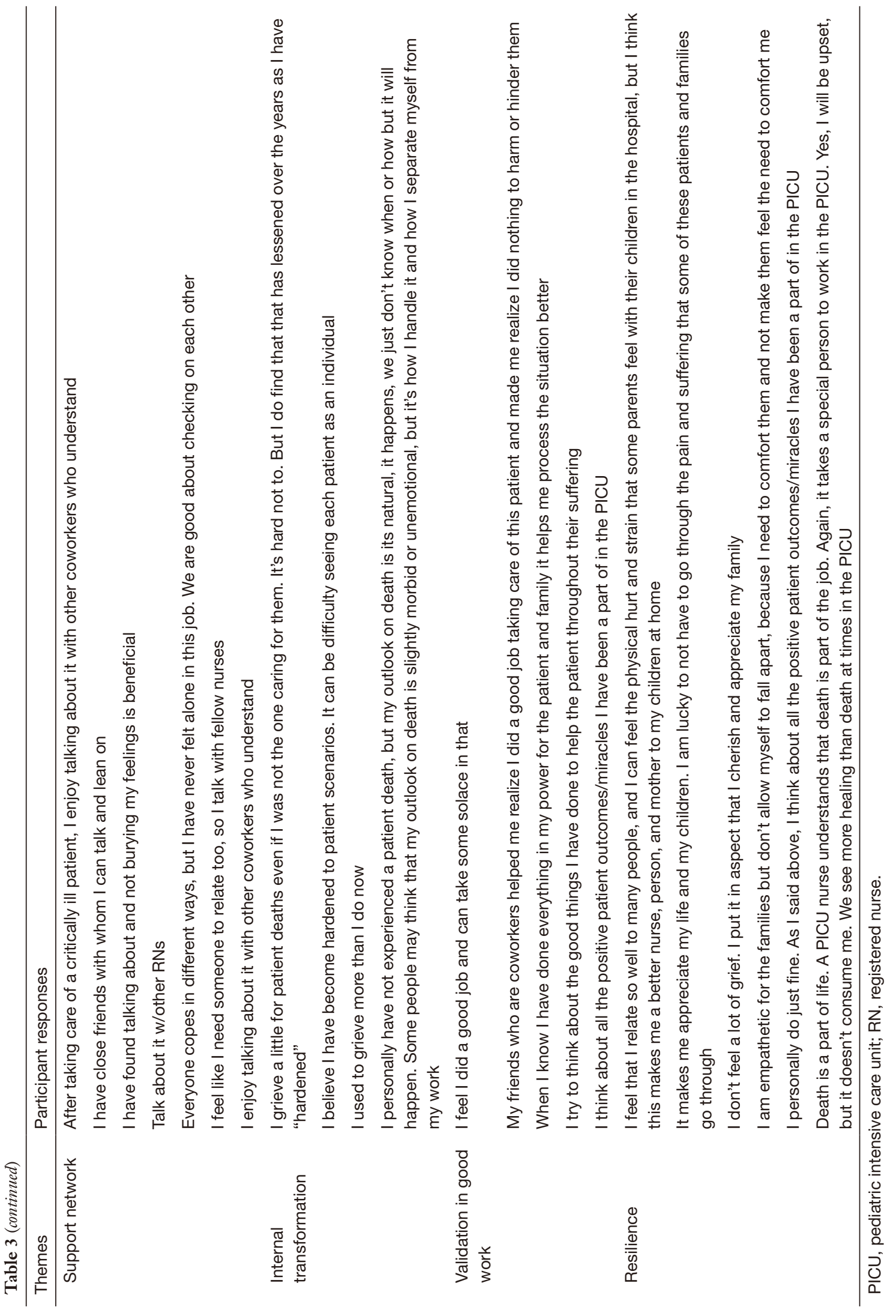


patient suffering may compound or alleviate the level of emotional response dependent on perception. Some nurses commented, "My distress is over the suffering we inflict on patients by not allowing them to die. I'm significantly impacted by this" and "I feel very frustrated when patients suffer and nothing is being done to help or nothing more can be done. I feel defeated". Alternatively, other nurses explained, "When the patient has been suffering for a while, I somehow feel more at ease with their death" or "When a patient passes, I am able to acknowledge their suffering is over".

\section{Coping}

Nurses offered strategies they used to cope with the suffering and death of children in the PICU. Coping was further delineated into 4 subthemes, identified as (I) compartmentalization, (II) reliance on a support network, (III) internal transformation, and (IV) validation in providing quality care. Compartmentalization was described as, "It touches me, but I tend to leave work at work", and "I can manage these symptoms myself, almost like out of sight, out of mind". Coworkers were often identified as a source of support, highlighted by comments such as, "I feel like I need someone to relate to, so I talk with fellow nurses", "Everyone copes in different ways, but I have never felt alone in this job. We are good about checking on each other", and "After taking care of a critically ill patient, I enjoy talking about it with other coworkers who understand". Internal transformation described the change over time in how nurses steeled themselves so losses had less effect on them, such as, "I believe I have become hardened to patient scenarios", "I do find that [grief] has lessened over the years as I have "hardened", and "I used to grieve more than I do now". Some nurses focus on the positive and find validation in work well done, such as "When I know I have done everything in my power for the patient and family, it helps me process the situation better" and "I think about all the positive patient outcomes/miracles I have been a part of in the PICU”. Again, additional participant quotes can be found in Table 3.

\section{Resilience}

A final theme identified by nurses reflected resilience. Resilience is a complex process encompassing optimism, realism, self-efficacy, and sometimes humor, which are all represented in the study data (27). Nurses shared many examples of resilience, such as resilience through selfefficacy, "I don't feel a lot of grief. I put it in aspect that I cherish and appreciate my family". As well as resilience through optimism, "I am lucky to not have to go through the pain and suffering that some of these patients and families go through". Lastly, resilience through realism, "Death is a part of life. A PICU nurse understands that death is a part of the job. Again, it takes a special person to work in the PICU...". Resilience is important to successfully adapt and prosper as a PCC nurse. Please refer to Table 3 for additional quotes supporting the theme of resilience.

\section{Discussion}

Pediatric nurses caring for children who die may experience grief after the death of a patient (20). Reactions to patient death swing along a pendulum that is influenced by many factors. In this qualitative analysis, we aimed to identify unifying themes in the grief reactions of pediatric critical care nurses, to develop a better understanding of the emotional distress experienced by bedside staff amid patient suffering and/or death. Based upon participant responses describing grief and distress after the suffering or death of a patient in the PICU, we identified four major themes, each with associated subthemes; (I) a continuum of emotional responses (limited, transient, and persistent emotional responses), (II) emotional prompts (compounding versus alleviating prompts), (III) coping strategies (compartmentalization, support networks, internal transformation, and validation in good work), and (IV) resilience.

The first theme, continuum of emotional responses, demonstrated the significant variation in the level of emotional impact each nurse experienced after patient death/suffering $(28,29)$. The level of emotional response is dependent upon the nurses' own ability to process the death and grieve (30). Our study described this variation with subthemes that differentiated the temporal impact of emotional responses as limited, transient, or persistent/ intrusive. Symptoms of intrusive grief, such as nightmares, repetitive thoughts, or flashbacks, occur when a person's normal flow of thought is interrupted and dominated by unwanted thoughts or images related to a trauma (31). Though intrusions can be difficult to control, they are generally considered to be normal reactions in traumatic experiences, and most weaken and diminish over time (32). Some nurses may experience prolonged intrusions (e.g., "It 
is rare for me to have a night where I do not have some sort of dream about work, almost always distressing") that may have an impact on work or sleep. Difficulty processing these intense emotional responses may lead nurses to become disengaged at the bedside, or to attempt to avoid exposure to human suffering $(30,33,34)$.

Emotional prompts were found to either compound or alleviate grief. Relief of patient suffering alleviated nursing grief, while grief was magnified when nurses identified closely with families, had personal relationships with the patient and family, or perceived patient suffering. Personal history and relationships with patients and families lead to a caring bond and stronger attachment, which can exacerbate personal feelings of grief $(20,29,33)$. Families often desire continuity of nursing care from admission to patient death and beyond as a means of support and may feel their child's death was impersonal if too many new staff are present (35). Attempting to provide continuity for the family and patient enhances the nurse-family, nurse-patient relationship. Literature suggests that healthcare professionals experience grief after a patient death in ways that are similar to personal losses $(15,20,29)$. However, a recent NICU nursing study, using the Revised Grief Experience Survey, demonstrated lower levels of grief in bedside nurses when compared to family caregivers (36). In relation to patient suffering, grief may be compounded by feelings of guilt and powerlessness when providing what is perceived as futile care to patients $(29,37)$. Moral distress is a complex concept that occurs when an individual cannot follow through with actions they deem to be moral, which in turn compromises their own professional integrity (38). Unresolved moral distress in nurses is associated with emotional exhaustion and leaving the nursing profession (38). It may also compromise the quality of patient care (38). Alternatively, some nurses feel relief and peace when a terminally ill patient dies (29).

Although coping was not explicitly asked about in the survey, responses to our qualitative question unveiled coping as a theme when participants were asked to describe grief and distress following the suffering or death of a pediatric patient. This may be due to the emotional difficulty associated with coping after death and suffering (39). We further identified 4 subthemes which explained specific coping mechanisms identified within participant responses: compartmentalization, support network, internal transformation, and validation in good work. Compartmentalization or setting boundaries, helps maintain work-life balance (39). Multiple studies identify emotional disassociation as an important coping mechanism to promote longevity in one's nursing career and a method of protecting emotional well-being $(4,40)$. It is not always easy, however, to separate one's professional and personal life. Therefore, a reliable support network of understanding colleagues is important. The healthcare team is viewed as an important resource for management of grief (41). Coworker support can buffer against distress in nurses exposed to adverse events in the NICU, as casual and spontaneous conversations with coworkers provide support and an opportunity to discuss shared experiences with loss $(4,40,42)$. Over time, increased exposure to patient death may require nurses to undergo an internal transformation to decrease distress (43). Some nurses learn how to participate in the dying process without being overly involved emotionally, and they come to expect coping with death as part of the job. However, with repeated deaths, some nurses may become apathetic or complacent toward patient death and suffering, which can negatively affect patient care $(2,4)$. Lastly, coping also occurs through perceived caregiving benefits, or the extent to which providing care is meaningful. This idea was identified as validation in good work. Healthcare workers feel more prepared for a patient death when their provided healthcare is viewed positively (44). Nurses feel privileged and derive meaning from being present with people in their most intimate and vulnerable moments (45). Finding meaning in one's work makes the daily stressors easier to endure and results in positive feelings about work (46). The varied responses in our study illustrate how PICU nurses find different ways of dealing with stressors in the intensive care atmosphere, some which may be more adaptive in the long run than others.

The final identified theme was resilience. Resilience is a multidimensional characteristic reflecting an individual's ability to thrive in the face of adversity $(43,47,48)$. It can be a protective mechanism preventing psychological disorders in healthcare providers exposed to the stressful PICU environment (47), including the suffering and death of pediatric patients $(49,50)$. For example, many health care professionals approach their work with a high degree of commitment and meaning despite high levels of stress (51). More resilient nurses can create personal meaning when circumstances are painful, overwhelming, or unreasonable (49). Resilient nurses in our study found appreciation for life, family, and friends. They acknowledged that death is inevitable and recognized their role in the recovery and healing of other patients who survived. Coping and resilience are psychological 
concepts that are often equated with one another, though more recent work has highlighted that these two concepts appear to be distinct (52). Nursing responses in our study that reflected resilience were responses that showed longer term adaptation or recovery from experiences encountered at a child's end of life, while responses that demonstrated various forms of coping more often described actions that nurses utilized at the time, or close to the time, that a child died. Resilience is a quality that individuals can be taught. Bereavement support programs that promote adaptive coping, social connection, mindfulness practice (e.g., selfreflection), and self-awareness are programs that would help staff further develop resilience $(53,54)$.

Our findings must be considered in the context of several limitations. The use of an electronic survey rather than inperson interviews eliminated the opportunity for probing questions prompting additional participant explanation and clarification of responses. Additionally, the effect of possible confounding variables (e.g., sex, gender, race, ethnicity, and years of experience) were not evaluated and may have affected individual grief reactions. Although grief is a universal experience to loss, it is also highly individual or unique to different people, including PCC nurses. Future mixed method research with diverse samples would help to replicate findings.

\section{Conclusions}

This study aimed to provide a deeper understanding of the grief experiences of pediatric critical care nurses after patient suffering and/or death. There is universal acknowledgement and a growing acceptance of grief in the nursing profession, but limited research on the experiences of the pediatric critical care nurses. This qualitative study provides a rich, contextualized understanding of PCC nurses' grief experiences. The four themes and underlying subthemes unveiled areas of importance for nurse support programs, such as the necessity to know and recognize maladaptive grief responses, the importance of institutional peer support programs, and the value of teaching resilience amongst PCC nurses.

In conclusion, we found that after experiencing patient suffering and/or death, some PICU nurses reported symptoms consistent with grief and distress (e.g., intrusions), while others reported few, if any, symptoms of grief. The identification of intrusive symptoms of grief in PCC nurses indicates the need to recognize maladaptive emotional responses to loss and ensuring access to professional mental health services. The praise of peer support suggests a need for the development of institutional, structured peer support programs. Psychological and emotional support programs that focus on shared external experiences between staff and families may help staff navigate their grief. Lastly, resilience is a learnable protective mechanism, indicating the value of education in adaptive coping, mindfulness practice and meaning making. Implementing these programs may enhance the well-being and retention of skilled, experienced nurses in the PICU.

\section{Acknowledgments}

Portions of this work was presented virtually at the Society of Critical Care Medicine's $50^{\text {th }}$ Annual Critical Care Congress in February of 2021.

Funding: The work was supported by The Research Institute at Nationwide Children's Hospital (No. FP00002380 to $\mathrm{KG})$.

\section{Footnote}

Reporting Checklist: The authors have completed the SRQR reporting checklist. Available at https://apm.amegroups. com/article/view/10.21037/apm-21-3225/rc

Data Sharing Statement: Available at https://apm.amegroups. com/article/view/10.21037/apm-21-3225/dss

Conflicts of Interest: All authors have completed the ICMJE uniform disclosure form (available at https://apm. amegroups.com/article/view/10.21037/apm-21-3225/coif). KG reports that intramural grant funding for the study was received from The Research Institute at Nationwide Children's Hospital. The other authors have no conflicts of interest to declare.

Ethical Statement: The authors are accountable for all aspects of the work in ensuring that questions related to the accuracy or integrity of any part of the work are appropriately investigated and resolved. The study was conducted in accordance with the Declaration of Helsinki (as revised in 2013). The study was approved by the Institutional Review Board of Nationwide Children's Hospital (\#00000193), which includes ethical approval. Informed consent was obtained by participant decision to complete the electronic survey embedded within the participant information sheet. 
Open Access Statement: This is an Open Access article distributed in accordance with the Creative Commons Attribution-NonCommercial-NoDerivs 4.0 International License (CC BY-NC-ND 4.0), which permits the noncommercial replication and distribution of the article with the strict proviso that no changes or edits are made and the original work is properly cited (including links to both the formal publication through the relevant DOI and the license). See: https://creativecommons.org/licenses/by-nc-nd/4.0/.

\section{References}

1. van Mol MM, Kompanje EJ, Benoit DD, et al. The Prevalence of Compassion Fatigue and Burnout among Healthcare Professionals in Intensive Care Units: A Systematic Review. PLoS One 2015;10:e0136955.

2. Khalaf IA, Al-Dweik G, Abu-Snieneh H, et al. Nurses' Experiences of Grief Following Patient Death: A Qualitative Approach. J Holist Nurs 2018;36:228-40.

3. Plante J, Cyr C. Health care professionals' grief after the death of a child. Paediatr Child Health 2011;16:213-6.

4. Shorter M, Stayt LC. Critical care nurses' experiences of grief in an adult intensive care unit. J Adv Nurs 2010;66:159-67.

5. Rosa WE, Levoy K, Battista V, et al. Using the Nurse Coaching Process to Support Bereaved Staff During the COVID-19 Crisis. J Hosp Palliat Nurs 2021;23:403-5.

6. Kapoor S, Morgan CK, Siddique MA, et al. "Sacred Pause" in the ICU: Evaluation of a Ritual and Intervention to Lower Distress and Burnout. Am J Hosp Palliat Care 2018;35:1337-41.

7. Wilson J, Kirshbaum M. Effects of patient death on nursing staff: a literature review. Br J Nurs 2011;20:559-63.

8. Gilart E, Lepiani I, Núñez MJC, et al. When Nurses Become Patients. Validation of the Content of the Diagnostic Label Professional Traumatic Grief. Healthcare (Basel) 2021;9:1082.

9. Crowe S. Disenfranchised Grief in the PICU: Crying for Attention. Pediatr Crit Care Med 2017;18:e367-9.

10. Chew YJM, Ang SLL, Shorey S. Experiences of new nurses dealing with death in a paediatric setting: A descriptive qualitative study. J Adv Nurs 2021;77:343-54.

11. Houck D. Helping nurses cope with grief and compassion fatigue: an educational intervention. Clin J Oncol Nurs 2014;18:454-8.

12. Brosche TA. Death, dying, and the ICU nurse. Dimens Crit Care Nurs 2003;22:173-9.

13. Conte TM. Pediatric oncology nurse and grief education: a telephone survey. J Pediatr Oncol Nurs 2011;28:93-9.

14. Boyle DA. Countering compassion fatigue: a requisite nursing agenda. Online J Issues Nurs 2011;16:2.

15. Adwan JZ. Pediatric nurses' grief experience, burnout and job satisfaction. J Pediatr Nurs 2014;29:329-36.

16. Al-Majid S, Carlson N, Kiyohara M, et al. Assessing the Degree of Compassion Satisfaction and Compassion Fatigue Among Critical Care, Oncology, and Charge Nurses. J Nurs Adm 2018;48:310-5.

17. Coetzee SK, Laschinger HKS. Toward a comprehensive, theoretical model of compassion fatigue: An integrative literature review. Nurs Health Sci 2018;20:4-15.

18. Meller N, Parker D, Hatcher D, et al. Grief experiences of nurses after the death of an adult patient in an acute hospital setting: An integrative review of literature. Collegian 2019;26:302-10.

19. Papadatou D. In the face of death : professionals who care for the dying and the bereaved. New York: Springer Pub. Co.; 2009.

20. Barnes S, Jordan Z, Broom M. Health professionals' experiences of grief associated with the death of pediatric patients: a systematic review. JBI Database System Rev Implement Rep 2020.

21. Betriana F, Kongsuwan W. Grief reactions and coping strategies of Muslim nurses dealing with death. Nurs Crit Care 2020;25:277-83.

22. Donnelly SM, Psirides A. Relatives' and staff's experience of patients dying in ICU. QJM 2015;108:935-42.

23. Mosheva M, Gross R, Hertz-Palmor N, et al. The association between witnessing patient death and mental health outcomes in frontline COVID-19 healthcare workers. Depress Anxiety 2021;38:468-79.

24. Santos RPD, Garros D, Carnevale F. Difficult decisions in pediatric practice and moral distress in the intensive care unit. Rev Bras Ter Intensiva 2018;30:226-32.

25. Dryden-Palmer K, Moore G, McNeil C, et al. Moral Distress of Clinicians in Canadian Pediatric and Neonatal ICUs. Pediatr Crit Care Med 2020;21:314-23.

26. Wetzel RC. Pediatric Intensive Care Databases for Quality Improvement. J Pediatr Intensive Care 2016;5:81-8.

27. Cooper AL, Brown JA, Rees CS, et al. Nurse resilience: A concept analysis. Int J Ment Health Nurs 2020;29:553-75.

28. Lee KJ, Dupree CY. Staff experiences with end-of-life care in the pediatric intensive care unit. J Palliat Med 2008; 11:986-90.

29. Lewis SL. Exploring NICU Nurses' Affective Responses to End-of-Life Care. Adv Neonatal Care 2017;17:96-105.

30. Gibson K, Hofmeyer A, Warland J. Nurses Providing 
End-of-Life Care for Infants and Their Families in the NICU: A Review of the Literature. Adv Neonatal Care 2018;18:471-9.

31. Simon NM. Treating complicated grief. JAMA 2013;310:416-23.

32. Shear MK. Grief and mourning gone awry: pathway and course of complicated grief. Dialogues Clin Neurosci 2012;14:119-28.

33. Missouridou E. Secondary Posttraumatic Stress and Nurses' Emotional Responses to Patient's Trauma. J Trauma Nurs 2017;24:110-5.

34. Wallbank S, Robertson N. Predictors of staff distress in response to professionally experienced miscarriage, stillbirth and neonatal loss: a questionnaire survey. Int J Nurs Stud 2013;50:1090-7.

35. Butler AE, Hall H, Copnell B. Gradually Disengaging: Parent-Health care Provider Relationships After a Child's Death in the Pediatric Intensive Care Unit. J Fam Nurs 2018;24:470-92.

36. Rodriguez A, Spilker A, Goyal D. Grief among Neonatal Intensive Care Nurses. MCN Am J Matern Child Nurs 2020;45:228-32.

37. Mu PF, Tseng YM, Wang CC, et al. Nurses' Experiences in End-of-Life Care in the PICU: A Qualitative Systematic Review. Nurs Sci Q 2019;32:12-22.

38. McAndrew NS, Leske J, Schroeter K. Moral distress in critical care nursing: The state of the science. Nurs Ethics 2018;25:552-70.

39. Zheng R, Lee SF, Bloomer MJ. How nurses cope with patient death: A systematic review and qualitative metasynthesis. J Clin Nurs 2018;27:e39-49.

40. Vega-Vega P, González-Rodríguez R, López-Encina $\mathrm{ME}$, et al. Perception of support in professional's and technician's grief of pediatric intensive care units in public hospitals. Rev Chil Pediatr 2019;90:429-36.

41. Wenzel J, Shaha M, Klimmek R, et al. Working through grief and loss: oncology nurses' perspectives on professional bereavement. Oncol Nurs Forum 2011;38:E272-82.

42. Winning AM, Merandi JM, Lewe D, et al. The emotional impact of errors or adverse events on healthcare providers in the NICU: The protective role of coworker support. J
Adv Nurs 2018;74:172-80.

43. Mealer M, Jones J, Meek P. Factors Affecting Resilience and Development of Posttraumatic Stress Disorder in Critical Care Nurses. Am J Crit Care 2017;26:184-92.

44. van Riesenbeck I, Boerner K, Barooah A, et al. Preparedness for Resident Death in Long-Term Care: The Experience of Front-Line Staff. J Pain Symptom Manage 2015;50:9-16.

45. Galuska L, Hahn J, Polifroni EC, et al. A Narrative Analysis of Nurses' Experiences With Meaning and Joy in Nursing Practice. Nurs Adm Q 2018;42:154-63.

46. Pavlish C, Hunt R. An exploratory study about meaningful work in acute care nursing. Nurs Forum 2012;47:113-22.

47. Mealer M, Jones J, Newman J, et al. The presence of resilience is associated with a healthier psychological profile in intensive care unit (ICU) nurses: results of a national survey. Int J Nurs Stud 2012;49:292-9.

48. Caldeira S, Timmins F. Resilience: synthesis of concept analyses and contribution to nursing classifications. Int Nurs Rev 2016;63:191-9.

49. Dryden-Palmer K, Garros D, Meyer EC, et al. Care for Dying Children and Their Families in the PICU: Promoting Clinician Education, Support, and Resilience. Pediatr Crit Care Med 2018;19:S79-85.

50. Whitehead PB, Herbertson RK, Hamric AB, et al. Moral distress among healthcare professionals: report of an institution-wide survey. J Nurs Scholarsh 2015;47:117-25.

51. Moreno-Milan B, Cano-Vindel A, Lopez-Dóriga P, et al. Meaning of work and personal protective factors among palliative care professionals. Palliat Support Care 2019;17:381-7.

52. Van der Hallen R, Jongerling J, Godor BP. Coping and resilience in adults: a cross-sectional network analysis. Anxiety Stress Coping 2020;33:479-96.

53. Gogo A, Osta A, McClafferty H, et al. Cultivating a way of being and doing: Individual strategies for physician wellbeing and resilience. Curr Probl Pediatr Adolesc Health Care 2019;49:100663.

54. Leng M, Xiu H, Yu P, et al. Current State and Influencing Factors of Nurse Resilience and Perceived Job-Related Stressors. J Contin Educ Nurs 2020;51:132-7.
Cite this article as: Groves KA, Adewumi A, Gerhardt CA, Skeens MA, Suttle ML. Grief in critical care nurses after pediatric suffering and death. Ann Palliat Med 2022;11(6):1888-1899. doi: 10.21037/apm-21-3225 